according to Hittorf its "active" and "inactive" states are not caused by resistant films, hence the asymmetrical effect of aluminum can only be caused by these; so that the theory of the action of the aluminum cell, as due to the formation of a resistant film, is confirmed.

\title{
REMARKS ON SOME METHODS OF DETERMINING CARBON IN STEEL.'
}

BY GFORGE AUCHY.

Received April $25,500 \%$

IN Blair's "Chemical Analysis of Iron"" it is stated that com1 bined carbon in steel can be determined by loss upon ignition, 70 per cent. of the loss representing the carbon. As Blair gives the percentage of carbon in the carbon sponge as "about" 70 per cent., and as the method is not in general use, it may be inferred that it is known to be inexact. Mr. George Dougherty, in the Iron Age for May I I, I 899, proposes a method which is identical except that the carbon sponge is washed four times with hot nitric acid (sp. gr. I.13) to dissolve out copper and copper sulphide. It may be questioned whether this procedure makes the method an accurate one as Mr. Dougherty's article does not throw much light on this point (only one result being given). Some experiments were made by the writer, which showed that, on the contrary, the washing with hot nitric acid is itself a source of error in one particular, and a possible source of error in another. I. The hot nitrc acid dissolves some of the carbon, and the amount dissolved varies with different steels. 2. The carbon sponge absorbs and retains a portion of the nitric acid, and this absorption is possibly not uniform in all cases. That the washing with hot nitric acid (sp. gr. I.I3) four times dissolves out carbon, and in varying amount, is shown in the following results, all from different steels:

1 Read at the February Meeting of the Ihiladelphia Section.

2 Blair's "Analysis of Iron." second edition, p. 151. 


\begin{tabular}{|c|c|c|c|}
\hline $\begin{array}{l}\text { By combus- } \\
\text { tion as } \\
\text { usual. } \\
\text { Per ceut. }\end{array}$ & $\begin{array}{c}\text { By combustion } \\
\text { but washed. } \\
\text { with hot } \\
\text { nitric acid. } \\
\text { Per cent. }\end{array}$ & $\begin{array}{l}\text { Per- } \\
\text { centage } \\
\text { of loss }\end{array}$ & $\begin{array}{c}\text { Carbon sponge } \\
\text { boiled up or } \\
\text { digested with } \\
\text { hot nitric } \\
\text { acid. }\end{array}$ \\
\hline 1.078 & $\mathrm{I} . \mathrm{O}_{3}$ & 4.45 & $\cdots$ \\
\hline 0.76 & 0.76 & 0.00 & $\ldots$ \\
\hline 0.7 I 5 & 0.68 & $4 \cdot 90$ & $\cdots$ \\
\hline 0.72 & 0.697 & 3.20 & $\cdots$ \\
\hline $0.8 \mathrm{I}$ & 0.775 & $4 \cdot 32$ & 0.628 (Boiled up.) \\
\hline 0.665 & .... & $\ldots$ & 0.62 (Digested one-fourth hr.) \\
\hline 0.665 & $\ldots$ & $\ldots$ & is two hours.) \\
\hline
\end{tabular}

Eleven other similar results were obtained in which the lowest percentage of loss was 2.I5, and highest 5.74. On digesting a carbon sponge with hot nitric acid (sp. gr. I.I3), and filtering the filtrate after boiling to expel lower oxides of nitrogen, decolorized permanganate solution.

That the carbon sponge, when washed with hot nitric acid (sp. gr. I.13), absorbs and retains nitric acid, is indicated by the following restults:
(

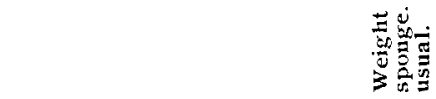
No. Gram.

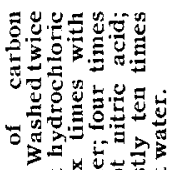
723
0.0856

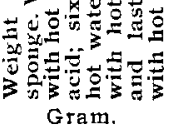
691
723
$\left\{0.058_{3}\right.$
$\left\{\begin{array}{l}0.0583 \\ 0.0583\end{array}\right.$
0.0856
0.0955
0.0654
0.0647
0.0880
739
0.0674
0.0747
BG 2
0.0603
0.0742
0.0679
0.0750
0.0740

No effort was made to ascertain whether the absorption was uniform in all cases. Instead the following determinations were made with a view to ascertaining the average percentage of carbon in the carbon sponge ${ }^{\prime}$ and also at the same time the range of error in the process.

1 Mr. Dougherty gives the percentage as 0.6750 . This does not represent the absolute percentage of carbon in the nitric acid-washed carbon sponge, but the absolute percentage, plus the loss of weight, in terms of carbot, suffered by the paper disk in being washed by acid liquids, plus the loss in weight through the solubility of the carbon in the hot nitric acid wash. Nor does the writer's average factor $(0.6000)$ teptesent the absolute percentage of carbon in the carbon sponge, but the percentage plus the loss by washing with hot nitric acid. The writer's filtrations were made through asbestos. 


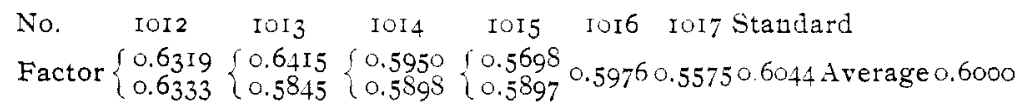

From the above it is seen that in a 0.60 per cent. carbon steel, results by this method might vary from 0.557 per cent. to $0.64 \mathrm{I}$ per cent. carbon, taking 0.6000 to be the factor. In the above tests only two washings with hot nitric acid (sp.gr. I.I3) in each case were made, in the lower row of tests, and three in the upper row to reduce the error from this cause as much as possible. The steels used were Swedish band saws containing not over 0.008 per cent. sulphur. If Meineke is right in considering the sulphur of the steel to be present in the carbon sponge in the free condition, ${ }^{1}$ another source of error must be connted against the process when used for high sulphur steels.

THE USUAL COMBUSTION METHOD.

Professor D. H. Browne, ${ }^{2}$ in describing the apparatus for the moist combustion method, says: "It is very necessary to have a small $\mathrm{U}$-tube containing $\mathrm{CaCl}_{2}$ in one leg and soda-lime in the other attached to the potash bulbs and weighed with them. The small straight tube designed to contain $\mathrm{CaCl}_{2}$ attached to the potash bulb is not sufficient to prevent the escape of a slight quantity of water from the potash solution." Mr. A. A. Blair, in using the dry method, found that the calcium chloride tube did not absorb all the moisture drawn over from the potash bulb. ${ }^{3}$ Mr. J. M. Camp, of Carnegie Steel Co., considers it necessary to have a weighed potash bulb containing strong sulphuric acid attached to the calcium chloride prolong." The writer of this article several years ago described to this Society some experiences of this kind in using the wet method of combustion. The carbon dioxide was not completely absorbed by the potash solution (sp.gr. 1.27), and the moisture not completely retained by the prolong and drying train; the a mount of moisture not retained by the drying train and passing into the potash bulb amounting to about 0.065 per cent. in terms of carbon with two sets of buibs and prolongs in use, was 0.045 per cent. for the first set usually, and 0.02 per cent. for the second, and a correction to this amount

1 Ztschr. angew. Chem. (1855), 376 .

2 J. Anal. Appl. Chem. $\mathbf{5}, 33 \mathrm{~s}$.

8 Ibia., 5, i2s.

4 "Methods of Iron Analysis." 
had to be made in each result. Professor Arnold also in his experience found a correction of 0.045 per cent. (using one bulb) to be necesssary. ${ }^{1}$ Professor Chas. F. Mabery found a loss of moisture and suspected a loss of carbon dioxide. ${ }^{2}$ This seems to be sufficient evidence that the usual drying and absorbing agencies are inefficient. On the other hand, many chemists using both methods of combustion, have, like Dr. Drown, satisfied themselves by actual trial of the efficiency of their apparatus in this respect. The writer himself upon changing to the dry method found no further difficulty of this kind of any great consequence ${ }^{3}$ except at first due to the copper oxide being packed into the preheating furnace too tightly, and aspiration being made by the pump. Mr. Buck, of the Bethlehem Steel Co., and Mr. Sargent, of the Carpenter Steel Works (the former with a Shimer apparatus, the latter with a modified oxygen apparatus), use extremely rapid rates of aspiration (allowing only twenty minutes for a combustion) without loss, either, of carbon dioxide or of moisture. Yet it is certain that those of us who have experienced a lack of efficiency of this sort have not simply dreamed or imagined it. What, then, is the reason that the potash solution sometimes fails to absorb all the carbon dioxide, and the calcium chloride or strong sulphuric acid fails to absorb all the moisture? Some recent experiments by the writer suggest an explanation and indicate a source of error, which though very simple may easily be overlooked. This source of error apparently lies in the fact that when there is undue resistance to the passage of gas through the apparatus for any reason, usually because of the calcium chloride or copper oxide having become clogged up in use, or having been packed in too tightly, or too finely divided in the first place, the gas then bubbles through the potash solution and the strong sulphuric acid, and passes through the calcium chloride not evenly and regularly but the reverse, and although precisely the same volume of gas may pass through as in normal conditions, the contact of gas with drying and absorbing materials is obviously less than normal.

1 "Stee1 Works Analysis." Professor Arnold thinks this due to something generated in the combustion flask, but the writer obtained the same result by simply aspirating air through the apparatus for the same length of time.

2 This Journal, 20, 510 .

3 Some moisture escaped from the proiong after being in use a number of tests, but this is now believed to be due to a cause that will appear later on. 
This irregularity of action and accompanying loss may be due simply or mainly to the size and shape of the potash bulb, or may have its origin in the oxygen cylinder; but whatever the cause it seems to be a fact that when the gas does not pass freely and easily through the apparatus, and does not bubble evenly and regularly through the bulbs, loss ensues if a rapid or moderately rapid flow be allowed.

The experiments were as follows:

$\begin{array}{ccc} & \text { Prolong clogged up. } & \text { Prolong in good condition. } \\ \text { Carbon. } & \text { Carbon. } \\ \text { No } & \text { Per cent. } & \text { Per cert. } \\ \text { IOI2 } & 0.755 & 0.76 \\ \text { IOI3 } & 0.68 & 0.716 \\ \text { IOI5 } & 0.705 & 0.718\end{array}$

In the last experiment with clogged prolong the rate of speed of gas flow was diminished. With fresh calcium chloride in the prolong the following tests were made. The loss was believed to be due to the resistance offered to the passage of the gas by the 3 inches of rather closely packed copper oxide in the combustion tube.

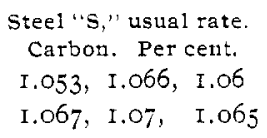

The first result under "usual rate" is not the writer's, but that of another chemist, and may perhaps be taken as an indication of some impediment to the flow of gas in his apparatus also. These results and the preceding ones seem to show that it is highly important to have the gas pass through the apparatus freely and easily if it is desired to maintain a rapid or moderately rapid rate of gas flow. Using another apparatus (a Shimer apparatus) in which the flow of gas is very free and unobstructed, no higher results could be obtained by using a slow rate than by using a rapid rate of gas flow. With the first-mentioned apparatus the writer now uses a rate of one bubble per second through the first or purifying bulb for one-half hour followed by ten minutes of a faster rate, and believes this rate slow enough not only to counteract the density of the copper oxide but also to allow for any clogging up of the calcium chloride that may occur; but this slow rate is, of course, impracticable where many combustions have to be crowded into 
a day, or when a combustion must be made in the very shortest possible time; when a rapid rate is employed it wonld seem imperative to be sure that the gas passes freely and easily through the apparatus, and bubbles regularly and evenly through the potash bulbs. Calcium chloride sometimes clogs up and strong sulphuric acid seems preferable. The writer believes that for the calcium chloride prolong, one could profitably substitute diminutive bulbs for strong sulphuric acid of the Geissler type but constructed to hang instead of to stand so as to allow of being weighed along with the potash bulbs by being suspended from the hook of the balance.

These experiments perhaps throw some light on the cause of the losses of carbon dioxide and moisture experienced by the writer in using the wet method of combustion. Possibly these losses were caused by some stoppage in the apparatus or irregularity of gas flow. As a matter of fact the aspiration (which took place from beginning to end of the process) was made by a filterpump which the writer has frequently observed does not exert an even and regular suction. Possibly all such losses are attributable (the drying and absorbing materials not being toe long in use) to some such cause-perhaps a clogging up somewhere in the apparatus causing an irregular and jerky gas flow; or perhaps too much apparatus, causing, by its resistance, an uneven flow.

Dr. P. W. Shimer has greatly simplified the dry combustion apparatus and his apparatus will, without doubt, eventually altogether displace the old form. He also makes a notable change in the direction of greater simplicity-in the drying and purifying train. A train which vies with Shimer's for simplicity is that of Prof. Arnold's described in his book, "Steel Works Analysis," but in other respects there is a remarkable difference between the two. Shimer's train : cold water for $\mathrm{HCl}$ and $\mathrm{Cl}$; calcium chloride for drying ; Arnold'strain : chromic acid solution for $\mathrm{SO}_{2}$; concentrated sulphuric acid for drying. It is seen that the difference is fundamental. The former is based upon the belief generally prevalent among American chemists that hydrochloric acid or chlorine, if present in the carbon sponge, is not absorbed by the copper oxide but passes out of the combustion tube, while sulphur dioxide is believed to be converted into sulphur trioxide in the pres- 
ence of the glowing copper oxide and absorbed by it. Prof. Arnold's belief is the exact opposite of this; namely, that hydrochloric acid and chlorine are absorbed by the copper oxide of the combustion tube (p.40), and that sulphur dioxide escapes therefrom unchanged. Which theory is correct? That hydrochloric acid, if present in the carbon sponge, is not absorbed by the copper oxide, and does pass ont of the combustion tube may easily be proved by testing the water of the Shimer absorption tube after a number of determinations have been made. On the other hand, as proof that sulphur dioxide passes out of the combustion tube, Arnold mentions an experiment in which potassium permanganate solution, placed after the combustion tube and connected with it, became decolorized by the gas. The writer finds that in using Arnold's chromic acid solution immediately following the combustion tube, as he directs, the chromic acid becomes entirely reduced, and the color of the solution changed to green after a considerable number of combustions have been made. But that this reduction is effected by hydrochloric acid, and not by sulphur dioxide, is believed to be proved by the fact that when a bulb containing cold water is interposed between the combustion tube and the chromic acid bulb, the color of the chromic acid solution does not change; nor does the water of the bulb preceding show any trace of sulphur dioxide when tested with permanganate solution. If traces of the gas ever escape absorption by the copper oxide, Shimer's cold water tube would seem to be an ample safeguard. But as a further precaution, concentrated sulphuric acid, saturated with chromic acid, may be substituted for calcium chloride in the train.

The fact observed in the examination of Dougherty's method, of the carbon sponge being slightly soluble in hot nitric acid, suggested the suspicion that it might also be soluble in hot acid double chloride solution to some extent. The following tests were made on the same sample of steel:

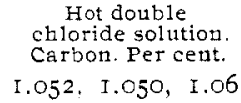

$$
\begin{aligned}
& \text { Cold double } \\
& \text { choloride solution. } \\
& \text { Carbou. Per cent. } \\
& \text { I.076, I.078, } 1.077
\end{aligned}
$$

In these tests the double chloride solution was heated (after

I Five drons (and probably less) of hydrochloric acid will completely reduce $10 \mathrm{cc}$ Arnold's chromic acid solution in the cold, standing over night. 
solution of precipitated copper was nearly complete) for an hour or more, giving a much severer test of the solubility of the carbon than would occur in actual practice. It may therefore be inferred that the error from this cause in actual practice is very slight or in some cases nothing, for as the second result of the first table of results in this article shows that the carbonaceous residues from some steels are unacted on by hot nitric acid, so it is probable that such residues resist the slightly solvent action of hot double chloride solution. On the other hand, some residues may be much more soluble in hot double chloride solution than those of the above table. The point brought out by these results is merely that heating the double chloride solution of the drillings is attended with some risk of loss.

The carbon residue of the first table, that was not acted on by hot uitric acid was from a saw-a much-worked product. The carbon residues from such finished products seem different from those of ingot steels inasmuch as they give much darker shades to nitric acid in the color test than do the latter; thus, for instance, a 1.07 per cent. carbon steel in a finished saw gave I.27 per cent. by the color test using a hammered slab as standard.

In washing the carbonaceous residue with hydrochloric acid it is perhaps safer to have the acid cold.

In carbon determinations, the error from moisture condensation in damp weather is well known. In a communication to the Society nearly two years ago the writer gave the results of experiments made in very damp weather which indicated the error from this cause to be usually 0.02 per cent. or 0.03 per cent., and occasionally as high as 0.05 and 0.06 per cent. When these experiments were made it was the writer's habit to have the balance-room door open; this door led into a small ante-room the door of which, at that time, also stood habitually open on account of warm weather, so that the outside air had access to the balance-room. For a long time back, however, the balanceroom door has been kept closed, at least during the progress of combustions, and no such excessive condensation as 0.05 per cent. and 0.06 per cent. have occurred, using extra bulbs as an indicator. It is therefore believed to be well to keep the balanceroom closed, at least in warm weather when adjoining parts of the laboratory are open. This is, of course, not an absolute 
preventive. Moisture condensations equivalent to something under 0.02 per cent. carbon may easily occur.

THE COLOR METHOD.

The color method for high carbon steels is generally regarded with much distrust. Mr. Wm. Metcalf in his book, "Steel", says: "For in high carbons the color test in the best hands is only the wildest guess work." It is the writer's experience that the same drillings, even when dissolved at the same time, frequently do not give the same shade, and that by performing the test in the usual way, results as high as o.ro per cent., or even higher, wide of the truth are often obtained. If the usual method be elaborated as follows, results not further from the truth than 0.03 per cent. (usually 0.01 or 0.02 per cent.), or at most 0.04 per cent. can uniformly be obtained: Duplicate tests of standard and samples are weighed out. Besides the standard, duplicate tests of two other steels in which the carbon has been accurately determined by combustion are also weighed out. In the absence of such steels, six samples of the standard are taken. When the color comparisons are made, the two steels of known carbon content are first tested, and from these tests is averaged a correction to be applied to all the results subsequently obtained. When these tests are finished the second sample of the standard is taken, the correction found as before, and the testing of the samples duplicated, and the average of these duplicates taken. These precautions are simple and obvious but are of no avail in the presence of a difficulty which, although it happens very rarely, still does happen. This difficulty is a carbon color showing a much deeper shade placed to the left of the standard than to the right of it, and requiring a further dilution equivalent to about 0 .ro per cent. carbon to make the shade to coincide with the standard, the color when placed to the right showing no change by this dilution, and still agreeing with the standard. The result is then too high by just the amount represented by this extra dilution, or about 0 . Io per cent., and it is necessary, therefore, when this abnormal shade is noticed, to discontinue the dilution and to take the reading when the color at the right coincides, ignoring the left-hand shade altogether. 

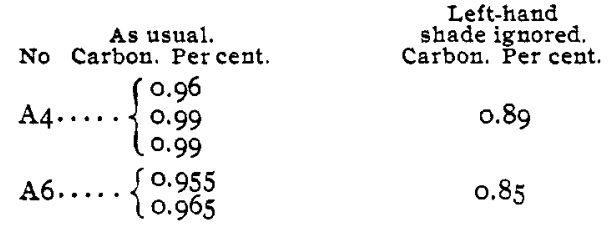

$$
\begin{aligned}
& \text { Combustion. } \\
& \text { Carbon. Per cent. } \\
& 0.88 \\
& \left\{\begin{array}{l}
0.85 \\
0.85
\end{array}\right.
\end{aligned}
$$

LABORATORY OF HENRY DISSTON AND SON'S STEEL WORKS,

peiladelphia, Pa.

\section{[CONTRIBUTION FROM THE LABORATORY OF ANAIYTICAI AND APPIIED CHEMISTRY, UNIVERSITY OF MICHIGAN.]}

\section{A BURETTE FOR ACCURATE GAS ANALYSIS.}

BY ALFRED H. WHITE.

Receired April 27, 3900.

FVERYONE who has attempted to make accurate analyses of E gases with the usual Hempel apparatus for technical gas analysis, knows there are many unavoidable sources of error, slight in themselves, but enough to make an exasperatingly large total at the end of a long analysis. The apparatus to be described was devised in the effort to eliminate some of these sources of inaccuracy. It is a modification of the Hempel burette with Petterson correction tube, the alterations being in the design of stop-cock and the position and form of the manometer, besides a change in the shape of the graduated tube to permit a more accurate reading of the gas volume. It has been used in its present form for the past year in this laboratory, and has been found to fulfil its purpose.

Some of the errors incident to analyses as usually conducted may be avoided by well-known precautions. If mercury instead of water is used as the liquid in the burette, errors due to solubility of the gas in the burette liquid and errors in reading due to water adhering to the walls of the burette, vanish. Errors due to solubility of gas in the reagent of the absorption pipette may be minimized by the use of a small quantity of the reagent in a pipette otherwise filled with mercury and may be greatly lessened when using an ordinary pipette by saturating the absorbing liquid with gas like that to be analyzed. Errors due to diffusion of gas through the liquid in the pipette are much more important than is usually believed, but may be obviated for most reagents by the use of a few cubic centimeters of mercury, 